stated in the paper (i.e. nearly two-thirds of the patients were tested before their first-ever ECT session). The results from this subgroup were not specifically reported, but we can now report on the most meaningful analysis on these patients (those who were tested before their first-ever ECT and tested again after they had $>12$ ECT sessions). This applies to 37 of the 55 patients who we reported in the paper as having had $>12$ ECT sessions (average of 21) between their first and their last tests (Table 2 in the paper). The results are basically indistinguishable from those reported in Table 2 , with the only significant change (an improvement) found again for the reaction time.

We welcome further research in this field, but want to reiterate that our results refer to cognitive performance, although retrograde memory problems do exist and can upset some patients. Such patients feel more reassured when they are able to compare their performance on cognitive tests pre- and post-ECT.

George Kirov, MRCPych, PhD, MRC Centre for Neuropsychiatric Genetics and Genomics, Cardiff University, Hadyn Ellis Building, Maindy Road, Cardiff. Email: Kirov@cardiff.ac.uk; Maria Atkins, MRCPsych, Cardiff and Vale University Health Board, Whitchurch Hospital, Cardiff, UK

doi: 10.1192/bjp.209.1.84a

\section{Defining clinically significant change}

I congratulate ter Heide et al on conducting an extremely timely and important clinical trial. ${ }^{1}$ As stated by the authors, there is a conspicuous lack of clinical trials investigating the effect of eye movement desensitisation and reprocessing (EMDR) in treating traumatised refugees.

However, in order to be able to appraise/interpret the results more fully, it would be of great value if the authors could analyse their data with different cut-off points for defining clinically significant change. In their article, the authors define clinically significant change as a decrease of 10 points or more on the Clinician-Administered PTSD Scale (CAPS). ${ }^{2}$ The authors report that approximately $40 \%$ of patients in both conditions achieved clinically significant improvement (Table 2).

However, there is currently no widely agreed threshold for defining clinically significant change on the CAPS and different clinical trials have used a range of different cut-off scores. For example, in two major publications Schnurr et $a l^{3,4}$ defined clinically significant change as a decrease of at least 10 points in total CAPS scores. Hinton et $a l^{5}$ used the rationally derived 15 -point change ${ }^{2}$ as a marker of clinically significant change. In line with the method set forth by Jacobson \& Truax, ${ }^{6}$ Taylor et $\mathrm{al}^{7}$ defined clinically significant change as a reduction in total CAPS score of at least two standard deviations. Hien et $a l^{8}$ used a 30-point or greater improvement on the CAPS to determine clinically significant improvement of PTSD symptoms, whereas Bryant et $a l^{9}$ defined clinically significant change as a cut-off of $<45$ on the CAPS at follow-up.

It is also important to take into consideration the measurement variability of the instrument. ${ }^{6}$ A change of 10 points on the CAPS is not necessarily even reliable. Monson et al ${ }^{10}$ calculated a reliable change score of 12.22 points on the CAPS, and we previously have calculated a conservative reliable change score of 14.3 points. ${ }^{11}$ So a change of 10 points might simply be within the measurement variability of the CAPS.

These issues taken together, it would be very informative if the authors made use of different cut-off scores for defining clinically significant change. The Institute of Medicine ${ }^{12}$ notes that common methods to define clinically significant change on the CAPS in the treatment literature are to define it as a $\geqslant 10$-point decrease, a $\geqslant 30$ percent decrease, or as two standard deviations below pretreatment level. Using a 30\% decrease in total CAPS score for the present sample entails a cut-off score for clinically significant change of approximately 23 points. Using two standard deviations below pre-treatment level ${ }^{6}$ as a marker for clinically significant change entails a cut-off score of approximately 36 points. It would be very informative if the authors re-analysed their data with at least these two thresholds for defining clinically significant change in addition to the 10-point cut-off score reported in their paper.

1 ter Heide FJJ, Mooren TM, van de Schooot R, de Jongh A, Kleber RJ. Eye movement desensitisation and reprocessing therapy $\mathrm{v}$. stabilisation as usual for refugees: randomised controlled trial. Br J Psychiatry 2016; doi: 10.1192/ bjp.bp.115.167775.

2 Weathers FW, Keane TM, Davidson JR. Clinician-administered PTSD scale: a review of the first ten years of research. Depress Anxiety 2001; 13: 132-56.

3 Schnurr PP, Friedman MJ, Engel CC, Foa EB, Shea MT, Chow BK, et al. Cognitive behavioral therapy for posttraumatic stress disorder in women: a randomized controlled trial. JAMA 2007; 297: 820-30.

4 Schnurr PP, Friedman MJ, Foy DW, Shea MT, Hsieh FY, Lavori PW, et al. Randomized trial of trauma-focused group therapy for posttraumatic stress disorder: results from a Department of Veterans Affairs Cooperative Study. Arch Gen Psychiatry 2003; 60: 481-9.

5 Hinton DE, Chhean D, Pich V, Safren SA, Hofmann SG, Pollack MH. A randomized controlled trial of cognitive-behavior therapy for Cambodian refugees with treatment-resistant PTSD and panic attacks: a cross-over design. J Traum Stress 2005; 18: 617-29.

6 Jacobson NS, Truax P. Clinical significance: A statistical approach to defining meaningful change in psychotherapy research. J Consult Clin Psychol 1991; 59: 12-9.

7 Taylor S, Thordarson DS, Maxfield L, Fedoroff IC, Lovell K, Ogrodniczuk J. Comparative efficacy, speed, and adverse effects of three PTSD treatments: exposure therapy, EMDR, and relaxation training. J Consult Clin Psychol 2003; 71: $330-8$.

8 Hien DA, Wells EA, Jiang H, Suarez-Morales L, Campbell ANC, Cohen LR, et al. Multisite randomized trial of behavioral interventions for women with co-occurring PTSD and substance use disorders. J Consult Clin Psychol 2009; 77: $607-19$.

9 Bryant RA, Moulds ML, Guthrie RM, Dang ST, Mastrodomenico J, Nixon RDV, et al. A randomized controlled trial of exposure therapy and cognitive restructuring for posttraumatic stress disorder. J Consult Clin Psychol 2008; 76: 695-703.

10 Monson CM, Schnurr PP, Resick PA, Friedman MJ, Young-Xu Y, Stevens SP. Cognitive processing therapy for veterans with military-related posttraumatic stress disorder. J Consult Clin Psychol 2006; 74: 898-907.

11 Halvorsen Jø, Stenmark H. Narrative exposure therapy for posttraumatic stress disorder in tortured refugees: a preliminary uncontrolled trial. Scand J Psychol 2010; 51: 495-502.

12 Institute of Medicine. Treatment of Posttraumatic Stress Disorder: An Assessment of the Evidence. National Academies Press, 2008: p. 224.

Joar øveraas Halvorsen, PhD, authorised clinical psychologist, St. Olavs Hospital, Trondheim University Hospital, Norway. Email: joar.halvorsen@svt.ntnu.no

doi: 10.1192/bjp.209.1.85

Authors' reply: Dr Halvorsen quite rightly draws attention to the various definitions of clinically significant change, which all have their advantages and disadvantages. We especially agree with the comment that the threshold for clinically significant change should at least coincide with the threshold for reliable change (18.66 in our sample). However, using the threshold of 10 points, as promoted by Schnurr, ${ }^{1}$ has specific value in our study. First, the 10 -point threshold has been shown to be related to changes in quality of life in several samples. ${ }^{2,3}$ Second, clinically significant change refers to both clinical improvement and deterioration. Most clinicians and researchers would agree that a deterioration 